\title{
The Role of Presepsin in Predicting Severe Coronavirus Disease-2019 Pneumonia Prognosis
}

\author{
(D) Mehmet Emin Pișkinpaşa \\ University of Health Sciences Turkey, İstanbul Training and Research Hospital, Clinic of Internal Medicine, İstanbul, Turkey
}

\begin{abstract}
Introduction: There are several biomarkers to predict disease severity in Coronavirus disease-2019 (COVID-19); however, more precise biomarkers are still needed to evaluate the disease course. This study aimed to evaluate a potential biomarker, a soluble cluster of differentiation 14 subtype (SCD14-ST, Presepsin), to predict the disease prognosis in severe COVID-19 pneumonia.

Methods: This study included 60 randomly selected patients, whose diagnosis was confirmed with severe acute respiratory syndromecoronavirus-2 nucleic acid reverse transcription-polymerase chain reaction and who were hospitalized with severe COVID-19 pneumonia, and 25 healthy controls. All patients' clinical and laboratory data were recorded. On day 1 after admission, venous blood samples were tested for C-reactive protein (CRP), procalcitonin, fibrinogen, hemogram, presepsin, and other laboratory tests (creatinine, aspartate aminotransferase, alanine transaminase, creatine kinase, lactate dehydrogenase, and electrolytes). Mortality rate, intubation rate, and duration of continuous $\mathrm{O}_{2}$ treatment were recorded. Results were evaluated with Statistical Package for the Social Sciences.

Results: This study included 60 patients with COVID-19 infection as the patient group and 25 participants in the control group, with a total of 85 participants. The mean presepsin levels were significantly higher in the patient group compared to the control group $(1.483 \pm 0.147 \mathrm{ng} / \mathrm{mL}$ vs $0.873 \pm 0.103 \mathrm{ng} / \mathrm{mL})$. Presepsin levels had a weak positive correlation with CRP levels and a strong correlation with procalcitonin levels and creatinine levels. In the patient group, 53 participants have recovered and were discharged, whereas 7 died. No significant difference was found for the presepsin levels in recovering and dying patients in the patient group.

Conclusion: New biomarkers are needed to predict prognosis and mortality in severe COVID-19. Presepsin might be promising to predict disease severity in patients with severe COVID-19, especially in special groups, such as patients with chronic renal failure.
\end{abstract}

Keywords: COVID-19 pneumonia, presepsin, biomarkers of prognosis

\section{Introduction}

The infection caused by severe acute respiratory syndrome-coronavirus-2 (SARS-CoV-2), which is known as Coronavirus disease-2019 (COVID-19) started in 2019 and turned into a pandemic in a short period. It became a massive public health problem causing serious morbidity and mortality with a SARS that affects millions of people worldwide. The infection is clinically presented in different forms ranging from an asymptomatic state to fatal pneumonia that causes mortality (1). Additionally, several laboratory tests [ferritin, neutrophil-to-lymphocyte ratio, fibrinogen, D-dimer, and C-reactive protein (CRP)] are used to detect disease severity and prognosis.

Presepsin is a soluble cluster of differentiation (CD) 14 subtype in glycoprotein form that is secreted from the monocytes and macrophages. Its serum level is elevated in $2 \mathrm{~h}$ following infection and reaches pick concentration in 2-4 h. Its half-life is 4-6 h (2). It is a candidate biomarker for early diagnosis and prognosis prediction in systemic infections.
This study aimed to evaluate presepsin to predict the disease prognosis in severe COVID-19 pneumonia and its relationship with other known inflammatory markers.

\section{Methods}

This study includes 60 randomly selected patients, whose diagnosis was confirmed with SARS-CoV-2 nucleic acid reverse transcription-polymerase chain reaction and who met severe pneumonia criteria according to the Living guidance for clinical management of COVID-19 (3) and were hospitalized in our internal medicine clinic, and 25 age-gender matched healthy controls.

All patients' clinical and laboratory data were recorded. On day 1 after admission, venous blood samples were tested for CRP, procalcitonin, hemogram, presepsin, and other laboratory tests [creatinine, aspartate aminotransferase, alanine transaminase (ALT), creatine kinase (CK), lactate dehydrogenase (LDH), and electrolytes]. 
Blood samples from the patients and controls were collected in Sarstedt S-Monovette ${ }^{\circledR}$ vacutainer tubes (Sarstedt AG \& Co., Germany, Lot no: 1030421) and centrifuged at $1500 \times \mathrm{g}$ for $10 \mathrm{~min}$. The serum was then stored at $-80{ }^{\circ} \mathrm{C}$ until the laboratory analysis. Presepsin levels (ng/ $\mathrm{mL}$ ) were measured by the sandwich enzyme-linked immunoassay method using the human presepsin kit (MyBioSource, USA, Katalog No: MBS766136).

Mortality rate, intubation rate, and duration of continuous 02 treatment were recorded. Results were evaluated with SPSS.

This study was approved by the Ethics Committee of the University of Health Sciences Turkey, İstanbul Training and Research Hospital (approval number: 2801, date: 02.04.2021). All participants provided written informed consent. All procedures performed in the study followed the 1964 Helsinki Declaration.

\section{Statistical Analysis}

Statistical analyses were performed using SPSS version 25.0. Categorical variables were defined as frequency and percentage rate, and numerical variables were determined as mean \pm standard deviation. The Kolmogorov-Smirnov test assessed the normality of the distribution of the quantitative variables. The Student's t-test was performed for normally distributed numeric variables, and the Mann-Whitney $U$ test was performed for non-normally distributed data for independent group comparison. Bivariate correlations were expressed by Pearson's or Spearman's correlation analyses when indicated. Statistically significant results were defined with a $p$-value of $<0.05$

\section{Results}

This study included 60 patients with COVID-19 infection as a patient group [female/male (F/M): 25/35] and 25 control (F/M: 10/15) group, with a total of 85 participants. The mean age was $53.1 \pm 9.0$ years in the patient group and $52.1 \pm 10.4$ years in the control group. The characteristics of the patient group in terms of clinical and laboratory findings are shown in Table 1. The mean presepsin levels were significantly higher in the patient group compared to the control group $(1.483 \pm 0.147 \mathrm{ng} / \mathrm{mL}$ vs $0.873 \pm 0.103 \mathrm{ng} / \mathrm{mL})(p=0.006)$. The mean CRP, procalcitonin, and ferritin levels were significantly higher in the patient group compared to the control group. The evaluation of the correlation between presepsin levels and clinical and laboratory parameters in the patient group is summarized in Table 2. In the patient group, 53 participants have recovered and were discharged, whereas 7 died. No significant difference was found for presepsin levels in recovering and dying patients in the patient group. The duration of hospitalization was significantly shorter in the dying group compared to the recovering group. Presepsin level had a weak positive correlation with CRP levels $(r=0.283, p<0.037)$ and strong correlation with procalcitonin levels $(r=0.573, p<0.001)$ and creatinine levels $(r=0.417, p<0.001)$ (Table 3$)$ in the patient group.

\section{Discussion}

Severe COVID-19 pneumonia is a serious clinical condition with increased mortality due to respiratory failure. Severe and persistent immune activation causes the secretion of several cytokines and a
Table 1. Characteristics of patients in terms of clinical and laboratory findings in the whole study group

\begin{tabular}{|c|c|c|c|}
\hline$(n=85)$ & $\begin{array}{l}\text { Patient group } \\
\text { (mean } \pm \text { SD or } \\
\text { N) }(n=60)\end{array}$ & $\begin{array}{l}\text { Control group } \\
\text { (mean } \pm \text { SD or } \\
\text { N) }(n=25)\end{array}$ & $p$ \\
\hline Age (years) & $53.1 \pm 9.0$ & $52.1 \pm 10.4$ & NS \\
\hline Female/male & $25 / 35$ & $10 / 15$ & NS \\
\hline Recovering/exitus & $53 / 7$ & - & - \\
\hline Presepsin (ng/mL) & $1.483 \pm 0.147$ & $0.873 \pm 0.103$ & 0.006 \\
\hline $\mathrm{CRP}(\mathrm{mg} / \mathrm{L})$ & $79.9 \pm 60.6$ & $3.6 \pm 1.5$ & $<0.001$ \\
\hline Procalcitonin (ng/mL) & $0.13 \pm 0.08$ & $0.018 \pm 0.005$ & $<0.001$ \\
\hline WBC $\left(10^{3} / \mathrm{uL}\right)$ & $6199.3 \pm 3252.2$ & $6880.1 \pm 751.7$ & $<0.001$ \\
\hline LYM $\left(10^{3} / \mathrm{uL}\right)$ & $1363.2 \pm 682.9$ & $2226.6 \pm 264.2$ & $<0.001$ \\
\hline HGB (g/dL) & $12.7 \pm 1.4$ & $13.4 \pm 1.1$ & NS \\
\hline Urea (mg/dL) & $31.1 \pm 17.3$ & $21.1 \pm 4.8$ & $<0.001$ \\
\hline Creatinine (mg/dL) & $0.8 \pm 0.3$ & $0.7 \pm 0.2$ & NS \\
\hline AST (U/L) & $44.3 \pm 30.7$ & $39.9 \pm 14.4$ & NS \\
\hline $\operatorname{ALT}(\mathrm{IU} / \mathrm{L})$ & $37.5 \pm 16.7$ & $32.4 \pm 13.1$ & NS \\
\hline LDH (U/L) & $329.9 \pm 111.4$ & $153.3 \pm 50.8$ & $<0.001$ \\
\hline CK (U/L) & $246.0 \pm 463.8$ & $116.8 \pm 68.4$ & $<0.001$ \\
\hline Ferritin (ng/mL) & $374.2 \pm 358.5$ & $60.8 \pm 37.6$ & $<0.001$ \\
\hline $\begin{array}{l}\text { Hospitalization time (days) } \\
\text { (oxygen-dependent days) }\end{array}$ & $9.7 \pm 6.5$ & & \\
\hline \multicolumn{4}{|c|}{$\begin{array}{l}\mathrm{P}<0.05 \text { statistically significant. Significant p-values are shown in bold. CRP: C-reactive } \\
\text { protein, WBC: white blood cell, LYM: Iymphocytes, HGB: hemoglobin, AST: aspartate } \\
\text { aminotransferase, ALT: alanine aminotransferase, LDH: lactate dehydrogenase, CK: } \\
\text { creatine kinase, SD: standard deviation }\end{array}$} \\
\hline
\end{tabular}

Table 2. Correlation between presepsin levels with clinical and laboratory parameters in the patient group

\begin{tabular}{|l|l|l|}
\hline & \multicolumn{2}{|l|}{$\begin{array}{l}\text { Presepsin levels (ng/ } \\
\mathbf{m L})\end{array}$} \\
\hline (n=60) & $\mathbf{r}$ & $\mathbf{p}$ \\
\hline Age (years) & -0.068 & 0.637 \\
\hline Male gender & -0.276 & $\mathbf{0 . 0 4 1}$ \\
\hline CRP (mg/L) & 0.283 & $\mathbf{0 . 0 3 7}$ \\
\hline Procalcitonin (ng/mL) & 0.573 & $<\mathbf{0 . 0 0 1}$ \\
\hline WBC (103/uL) & -0.158 & 0.249 \\
\hline LYM (103/uL) & -0.172 & 0.209 \\
\hline HGB (g/dL) & 0.074 & 0.593 \\
\hline Urea (mg/dL) & 0.495 & $<\mathbf{0 . 0 0 1}$ \\
\hline Creatinine (mg/dL) & 0.417 & $<\mathbf{0 . 0 0 1}$ \\
\hline AST (U/L) & 0.142 & 0.305 \\
\hline ALT (IU/L) & 0.071 & 0.609 \\
\hline LDH (U/L) & 0.192 & 0.165 \\
\hline $\begin{array}{l}\text { CK (U/L) } \\
\text { aminotransferase, ALT: alanine aminotransferase, LDH: lactate dehydrogenase, CK: }\end{array}$ \\
\hline Ferritin (ng/mL) & 0.060 & 0.668 \\
\hline Hospitalization time (oxygen dependent) (days) & -0.284 & 0.155 \\
\hline Preatine kinase & $\mathbf{0 . 0 4 1}$ \\
\hline
\end{tabular}




\begin{tabular}{|c|c|c|c|}
\hline & $\begin{array}{l}\text { Patients who } \\
\text { recovered }\end{array}$ & $\begin{array}{l}\text { Patients who } \\
\text { died }\end{array}$ & \\
\hline$(n=60)$ & $(n=53)$ & $(n=7)$ & p \\
\hline Age (years) & $52.6 \pm 9.3$ & $57.3 \pm 5.5$ & NS \\
\hline Female/male & $23 / 30$ & $2 / 5$ & - \\
\hline Presepsin (pg/mL) & $1.3 \pm 0.9$ & $2.4 \pm 2.0$ & NS \\
\hline CRP $(m g / L)$ & $70.6 \pm 56.3$ & $150.7 \pm 45.2$ & 0.001 \\
\hline Procalcitonin (ng/mL) & $0.12 \pm 0.07$ & $0.15 \pm 0.10$ & 0.043 \\
\hline WBC (103/uL) & $6031.4 \pm 3184.1$ & $7170.0 \pm 3741.3$ & NS \\
\hline LYMPH $\left(10^{3} / \mathrm{uL}\right)$ & $1396.8 \pm 715.8$ & $1108.6 \pm 243.6$ & NS \\
\hline $\mathrm{HGB}(\mathrm{g} / \mathrm{dL})$ & $12.8 \pm 1.3$ & $11.8 \pm 2.0$ & NS \\
\hline Urea (mg/dL) & $30.2 \pm 16.8$ & $38.4 \pm 21.1$ & NS \\
\hline Creatinine (mg/dL) & $0.8 \pm 0.3$ & $1.0 \pm 0.4$ & NS \\
\hline AST (U/L) & $43.6 \pm 32.1$ & $49.1 \pm 17.8$ & NS \\
\hline ALT (IU/L) & $37.2 \pm 28.1$ & $38.9 \pm 12.3$ & NS \\
\hline $\mathrm{LDH}(\mathrm{U} / \mathrm{L})$ & $324.8 \pm 113.5$ & $369.0 \pm 92.8$ & NS \\
\hline CK (U/L) & $232.1 \pm 479.9$ & $347.6 \pm 331.8$ & NS \\
\hline Ferritin (ng/mL) & $349.1 \pm 339.8$ & $564.6 \pm 464.4$ & NS \\
\hline Hospitalization time (days) & $10.2 \pm 6.7$ & $6.1 \pm 2.4$ & 0.01 \\
\hline
\end{tabular}

clinical condition like hemophagocytic syndrome during the infection.

Several prognostic biomarkers are offered to predict the disease prognosis, including white blood cell, lymphopenia, CRP, and some biochemical parameters such as ALT, LDH, albumin, CK, D-dimer, and troponin $(4,5)$. However, more precise biomarkers are needed to predict morbidity and mortality earlier in patients with a serious infection.

CD14 is the receptor of lipopolysaccharide-lipopolysaccharide binding protein complexes. CD14 exists as a soluble (sCD14) and membraneassociated (mCD14) protein present on the surface of leukocytes. MCD14 is expressed on monocyte and macrophage surfaces and has a strong affinity for lipopolysaccharides (6). Soluble CD14 is found in plasma and it translates to the immune response of CD14 negative cells like the endothelium and epithelium cells (7). 13kDa N-terminal part creates CD14 subtype, which is called (sCD14-ST) presepsin (8). The role of presepsin in the human organism is yet unknown but is thought to have a contribution to an immune response with interaction with $T$ vs B cells (2).

Studies demonstrated presepsin as a biomarker for early diagnosis and prediction of prognosis in bacterial sepsis (9-12). Additionally, clinical and experimental studies revealed that presepsin levels are elevated in non-bacterial and fungal infections $(13,14)$.

Our study revealed a significantly higher presepsin level in the patient group than the control group. However, no statistically significant difference was found between patients who recovered and who died after the need for mechanical ventilation. This result needs to be supported with bigger studies.

Another study with a limited number of patients revealed higher levels of presepsin in patients who died in the intensive care unit and suggested its usage as a mortality predictor (15). Further, a study with a limited number of patients revealed the correlation of presepsin with disease severity in patients with COVID-19 (16). Dell'Aquila et al. (17) revealed that presepsin and troponin 1 were elevated in patients who died from COVID-19 and that it was a reliable biomarker to predict the 30-day mortality in patients with COVID-19.

Our study revealed a higher procalcitonin level in the patient group than the control group and a positive correlation with presepsin levels. Procalcitonin is elevated in serious bacterial infections and is used as a sepsis biomarker. Its biological effect is unclear; however, it has common sequence homology with tumor necrosis factor-alpha and interleukin-6 and is accepted as an inflammatory mediator (18). Procalcitonin elevation is shown in severe COVID-19 infection (19-22).

Chronic renal failure (CRF) increases mortality in severe COVID-19 infection (23). Our study revealed a strong correlation between presepsin and creatinine levels. Heart failure, renal failure, and class 3 obesity (body mass index of $\geq 40 \mathrm{~kg} / \mathrm{m}^{2}$ ) were related to hospital admissions and disease severity in COVID infection (24). Williamson et al. (25) searched the risk factors in COVID-19 infection in a wide range of patients and revealed that disease severity increases as the glomerular filtration rate (GFR) decrease. The mortality rate in this group was higher than the diabetic group and was correlated with GFR. The relationship between creatinine and presepsin levels in our study favors the immune dysregulation in patients with CRF.

\section{Conclusion}

New biomarkers are needed to predict the prognosis and mortality in severe COVID-19. Presepsin might be promising to predict the disease severity in patients with severe COVID-19, especially in groups with CRF.

Acknowledgments: We respectfully remember all the colleagues we lost in the COVID-19 battle. We also want to thank Assoc. Prof. Berrin Inal for her contribution to biochemical tests.

Ethics Committee Approval: This study was approved by the Ethics Committee of the University of Health Sciences Turkey, İstanbul Training and Research Hospital (approval number: 2801, date: 02.04.2021).

Informed Consent: All participants provided written informed consent. Peer-review: Externally and internally peer-reviewed.

Financial Disclosure: The author declared that this study received no financial support.

\section{References}

1. Velavan TP, Meyer CG. The COVID-19 epidemic. Trop Med Int Health 2020; 25: 278-80.

2. Chenevier Gobeaux C, Borderie D, Weiss N, Mallet-Coste T, Claessens YE. Presepsin (sCD14-ST), an innate immune response marker in sepsis. Clin Chim Acta 2015; 450: 97-103. 
3. World Health Organization. COVID-19 clinical management: living guidance. https://www.who.int/publications/i/item/WHO-2019nCoV-clinical-2021-1 (2021).

4. Zhang G, Zhang J, Wang B, Zhu X, Wang Q, Qiu S. Analysis of clinical characteristics and laboratory findings of 95 cases of 2019 novel coronavirus pneumonia in Wuhan, China: a retrospective analysis. Respir Res 2020; 21: 74.

5. Hu X, Hu C, Yang Y, Chen J, Zhong P, Wen Y, et al. Clinical characteristics and risk factors for severity of COVID-19 outside Wuhan: a doublecenter retrospective cohort study of 213 cases in Hunan, China.Ther Adv Respir Dis 2020; 14: 1753466620963035.

6. Grunwald U, Krüger C, Westermann J, Lukowsky A, Ehlers M, Schütt C. An enzyme-linked immunosorbent assay for the quantification of solubilized CD14 in biological fluids. J Immunol Methods 1992; 155: 225-32.

7. Shirakawa K, Naitou K, Hirose J, Takahashi T, Furusako S. Presepsin (sCD14-ST): development and evaluation of one-step ELISA with a new standard that is similar to the form of presepsin in septic patients. Clin Chem Lab Med 2011; 49: 937-9.

8. Mussap M, Noto A, Fravega M, Fanos V. Soluble CD14 subtype presepsin (sCD14-ST) and lipopolysaccharide binding protein (LBP) in neonatal sepsis: new clinical and analytical perspectives for two old biomarkers.J Matern Fetal Neonatal Med 2011; 24(Suppl2): 12-4.

9. Wu J, Hu L, Zhang G, Wu F, He T. Accuracy of Presepsin in Sepsis diagnosis: a systematic review and meta-analysis. PLoS One 2015; 10: e0133057.

10. Zheng Z, Jiang L, Ye L, Gao Y, Tang L, Zhang M. The accuracy of presepsin for the diagnosis of sepsis from SIRS: a systematic review and meta-analysis. Ann Intensive Care 2015; 5: 48.

11. Tong X, Cao Y, Yu M, Han C. Presepsin as a diagnostic marker for sepsis: evidence from a bivariate meta-analysis. Ther Clin Risk Manag 2015; 11: 1027-33.

12. Wu CC, Lan HM, Han ST, Chaou CH, Yeh CF, Liu SH, et al. Comparison of diagnostic accuracy in sepsis between presepsin, procalcitonin, and C-reactive protein: a systematic review and meta-analysis. Ann Intensive Care 2017; 7: 91.

13. Bamba Y, Moro H, Aoki N, Koizumi T, Ohshima Y, Watanabe S, et al. Increased presepsin levels are associated with the severity of fungal bloodstream infections. PLoS One 2018; 13: e0206089.

14. Bazhenov A, Galstian GM, Pashkova M, Konova Z, Drokov MY, Savchenko V. Stimulation of SCD14-ST (Presepsin) Secretion By
Peripheral Blood Mononuclear Cells after Candida Albicans Lysate and Lipopolysaccharide Exposure. Blood 2017; 130: 4811.

15. Zaninotto M, Mion MM, Cosma C, Rinaldi D, Plebani M. Presepsin in risk stratification of SARS-CoV-2 patients. Clin Chim Acta 2020; 507: 161-3.

16. Fukada A, Kitagawa Y, Matsuoka M, Sakai J, Imai K, Tarumoto N, et al. Presepsin as a predictive biomarker of severity in COVID-19: A case series. J Med Virol 2021; 93: 99-101.

17. Dell'Aquila P, Raimondo P, Orso D, De Luca P, Pozzessere P, Parisi CV, et al. A simple prognostic score based on troponin and presepsin for COVID-19 patients admitted to the emergency department: a singlecenter pilot study. Acta Biomed 2021; 92: e2021233.

18. Russwurm S, Wiederhold M, Oberhoffer M, Stonans I, Zipfel PF, Reinhart K. Molecular aspects and natural source of procalcitonin. Clin Chem Lab Med 1999; 37: 789-97.

19. Guan WJ, Liang WH, Zhao Y, Liang HR, Chen ZS, Li YM, et al. Comorbidity and its impact on 1590 patients with Covid-19 in China: a nationwide analysis. Eur Respir J 2020; 55: 2000547.

20. Zhang G, Hu C, Luo L, Fang F, Chen Y, Li J, et al. Clinical features and short-term outcomes of 221 patients with COVID-19 in Wuhan, China. J Clin Virol 2020; 127: 104364.

21. Chen T, Dai Z, Mo P, Li X, Ma Z, Song S, et al. Clinical characteristics and outcomes of older patients with coronavirus disease 2019 (COVID-19) in Wuhan, China (2019): a single-centered, retrospective study. J Gerontol A Biol Sci Med Sci 2020; 75: 1788-95.

22. Sun D, Li H, Lu XX, Xiao H, Ren J, Zhang FR, et al. Clinical features of severe pediatric patients with coronavirus disease 2019 in Wuhan: a single center's observational study. World J Pediatr 2020; 16: 251-9.

23. Cheng Y, Luo R, Wang K, Zhang M, Wang Z, Dong L, et al. Kidney disease is associated with in-hospital death of patients with COVID-19. Kidney Int 2020; 97: 829-38.

24. Petrilli CM, Jones SA, Yang J, Rajagopalan H, O’Donnell L, Chernyak Y, et al. Factors associated with hospital admission and critical illness among 5279 people with coronavirus disease 2019 in New York City: prospective cohort study. BMJ 2020; 369: m1966.

25. Williamson EJ, Walker AJ, Bhaskaran K, Bacon S, Bates C, Morton CE, et al. Factors associated with COVID-19-related death using OpenSAFELY. Nature 2020; 584: 430-6. 